\title{
A conjugate of pyridine-4-aldoxime and atropine as a potential antidote against organophosphorus compounds poisoning
}

\author{
Jasna Lovrić1 ${ }^{\star}$, Suzana Berend ${ }^{\star \star} \bowtie$, Ana Lucić Vrdoljak², Božica Radić2, Maja Katalinić2 \\ Zrinka Kovarik², Davor Želježić2, Nevenka Kopjar², Slavko Rast ${ }^{3}$ and Milan Mesić ${ }^{3}$ \\ IUniversity of Zagreb, School of Medicine, Zagreb, Croatia; Institute for Medical Research and Occupational Health, Zagreb, Croatia; ${ }^{3}$ Galapagos \\ Research Centre d.o.o., Zagreb, Croatia
}

\begin{abstract}
A conjugate of pyridine-4-aldoxime and atropine (ATR4-OX) was synthesized and its antidotal efficiency was tested in vitro on tabun- or paraoxon-inhibited acetylcholinesterase (AChE) of human erythrocytes as well as in vivo using soman-, tabun- or paraoxon-poisoned mice. Its genotoxic profile was assessed on human lymphocytes in vitro and was found acceptable for further research. ATR-4-OX showed very weak antidotal activity, inadequate for soman or tabun poisoning. Conversely, it was effective against paraoxon poisoning both in vitro and in vivo. All animals treated with $5 \%$ or $25 \% \mathrm{LD}_{50}$ doses of the new oxime survived after administration of 10.0 or $16.0 L_{50}$ doses of paraoxon, respectively. Based on the persistence of toxicity symptoms in mice, the atropine moiety had questionable effects in attenuating such symptoms. It appears that ATR-4-OX has a therapeutic effect related to the reactivation of phosphylated $\mathrm{AChE}$, but not to receptor antagonization.
\end{abstract}

Keywords: antidotal potential, atropine, genotoxicity, pyridine-4aldoxime, organophosphates

Received: 23 September, 2010; revised: 12 May, 2011; accepted: 09 June, 2011; available on-line: 13 June, 2011

\section{INTRODUCTION}

Organophosphorus compounds (OP) inhibit acetylcholinesterase (AChE) by phosphylating its catalytic serine at the active site. AChE inhibition causes accumulation of neurotransmitter acetylcholine (ACh) at the synapses, resulting in overstimulation of cholinergic receptors ( $\mathrm{Namba}$ et al., 1971). Due to the high mortality rate of OP poisoning, early diagnosis and appropriate treatment are often life saving. The current regimen for treatment of OP poisoning consists primarily of atropine to block the effect of excess $\mathrm{ACh}$ at muscarinic receptors (i.e., nausea, vomiting, diarrhoea and bowel movements) and an oxime to reactivate the inhibited AChE. Therapy with conventional oximes, such as pralidoxime (2-PAM), trimedoxime (TMB4), asoxime (HI-6) and obidoxime (LüH-6), has disadvantages either due to their inability to act as reactivators of AChE inhibited by some OP or due to their toxicity. The search for new potent reactivators led us to the synthesis of a conjugated compound based on three important fragments: pyridine-4-aldoxime, a butylene chain and atropine. The oxime group at position four in the pyridinium ring and the butylene linker have been shown to be beneficial structural characteristics against inhibition by OP in previous studies (Pang et al., 2003; Kim et al., 2005; Antonijević \& Stojiljković, 2007; Kovarik et al., 2007; Kovarik et al.,
2008; Kovarik et al., 2010). Furthermore, encouraged by the effectiveness of quaternized atropine as an antimuscarinic drug (Sugai et al., 1985; Schmeller et al., 1995), we combined this moiety with the oxime to create a compound that could potentially act as an antidote against OP poisoning.

The newly synthesized compound ATR-4-OX was investigated in parallel for its potency to reactivate tabun- or paraoxon-inhibited human erythrocyte $\mathrm{AChE}$ and for its therapeutic efficacy in soman-, tabun- or paraoxon-poisoned mice. Based on previous findings of the acceptable cytotoxic and genotoxic profile of HI-6 oxime (Radić et al., 2007), we conducted the same tests for ATR-4-OX.

\section{MATERIALS AND METHODS}

Synthesis. Design of the novel compound atropine-4pyridinealdoxime (ATR-4-OX) is shown in Fig. 1. Intermediate 4-pyridinecarbaldehyde oxime (1) was prepared according to Poziomek et al. (1958). The key intermediate [8-(4-bromobutyl)-3-[(3-hydroxy-2-phenylpropanoyl)oxy]-8methyl-8-azoniabicyclo[3.2.1]octane bromide] (2) is quaternized atropine prepared by the described method, using atropine and dibromobutane in acetonitrile at room temperature (Makarevich \& Gubin, 2006). The crude intermediate 2 containing the starting atropine was used in the following reaction without further purification. Bisquaternization with pyridine-4-aldoxime was achieved by reaction in acetonitrile at $80^{\circ} \mathrm{C}$ for three days. Intermediates $2(200 \mathrm{mg})$ and $1(100 \mathrm{mg}, 0.8 \mathrm{mmol})$ were dissolved in $10 \mathrm{ml}$ of acetonitrile and stirred at $80^{\circ} \mathrm{C}$ for three days. The solvent was then decanted and the residual brown oil was washed with acetonitrile $(20 \mathrm{ml})$ and purified by preparative HPLC. The product obtained after purification was converted to dichloride salt by dissolution in $\mathrm{HCl} 6 \mathrm{M}(5 \mathrm{ml})$ and lyophilization of the resulting solution. ATR-4-OX [8-(4-\{4-[(E)-(hydroxyimino) methyl]-1-pyridiniumyl $\}$ butyl)-3-[(3-hydroxy-2-phenylpropanoyl)oxy]-8-methyl-8-azoniabicyclo [3.2.1]octane dichloride] (3) (104 $\mathrm{mg}, 0.19 \mathrm{mmol})$ was obtained in the form of a white, highly hygroscopic powder. The purity

\footnotetext{
\e-mail: suzana@imi.hr

*The authors equally contributed to the paper.

Abbreviations: ACh, acetylcholine; AChE, acetylcholinesterase; ATCh, acetylthiocholine iodide; ATR-4-OX, atropine-4-pyridinealdoxime; DTNB, 5,5'-dithiobis(2-nitrobenzoic acid); HI-6, asoxime; hOGG, human 8-hydroxyguanine DNA-glycosylase; LüH-6, obidoxime; MDP, maximal dose of poison; 8-OhdG, 8-hydroxydeoxyguanosine; OP, organophosphorus compounds; 2-PAM, pralidoxime; PI, protective index: TMB-4, trimedoxime
} 

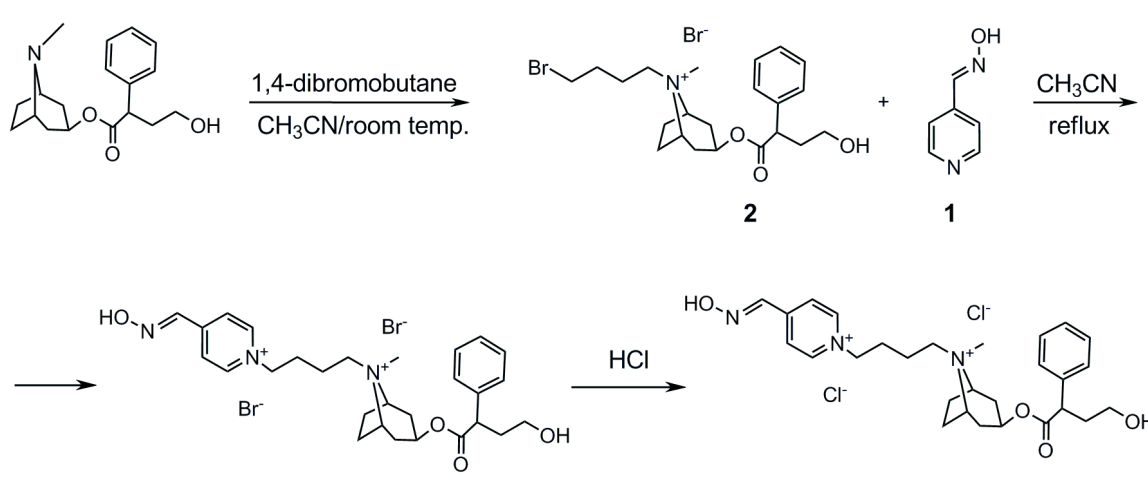

3 (dibromide)

Figure 1. Design of the novel compound ATR-4-OX

(1) 4-pyridinecarbaldehyde oxime; (2) 8-(4-bromobutyl)-3-[(3-hydroxy-2-phenylpropanoyl)oxy]-8methyl-8-azoniabicyclo[3.2.1]octane bromide; (3) 8-(4-\{4-[(E)-(hydroxyimino)methyl]-1-pyridiniumyl\} butyl)-3-[(3-hydroxy-2-phenylpropanoyl)oxy]-8-methyl-8-azoniabicyclo [3.2.1] octane dichloride

of the compound was at least $96 \%$, as determined by HPLC.

All solvents used were dried using the appropriate well known methods. Chemicals were used as received from Sigma-Aldrich, Inc., Steinheim, Germany, unless otherwise stated. 1,4-dibromobutane was distilled under reduced pressure prior to use. Reactions were performed under an argon atmosphere.

The progression of reactions was monitored on an analytical UPLC-MS/UV spectrophotometer (Waters Ultra performance LC). All analyses were carried out at $25^{\circ} \mathrm{C}$ using a $2.1 \mathrm{~mm} \times 50 \mathrm{~mm}, 1.7 \mu \mathrm{m}$, reversed phase Waters Acquity UPLC BEH C18 column and a binary eluent made from solution A $(0.1 \%$ formic acid in water) and solution B ( $0.1 \%$ formic acid in acetonitrile). This eluent was used as a gradient from $5 \%$ of solution $\mathrm{B}$ to $90 \%$ of solution B over 12 min. Flow rate was $1 \mathrm{ml} / \mathrm{min}$ (all solvents were HPLC grade, Merck \& Co., Inc., NJ, USA). The UPLC system was monitored with a DAD array detector at $254 \mathrm{~nm}$ and an SQD detector.

The final purity of the compounds was monitored on analytical HPLC-MS spectrophotometer (Waters 2690). All analyses were carried out at $25^{\circ} \mathrm{C}$ using a $3 \mathrm{~mm} \times 100 \mathrm{~mm}, 3.5 \mu \mathrm{m}$, reversed phase X-Terra C18 column and a binary eluent made from solution $\mathrm{A}$ and the solution B. This eluent was used as a gradient from $5 \%$ of solution B to $90 \%$ of solution B over $19.5 \mathrm{~min}$. Flow rate was $0.5 \mathrm{ml} / \mathrm{min}$. The HPLC system was monitored with a DAD array detector at $254 \mathrm{~nm}$ and a Micromass Quattromicro mass spectrometer.

HPLC-MS/UV purification was carried out at $25^{\circ} \mathrm{C}$ on a Waters auto purification system using a $19 \mathrm{~mm} \times 100 \mathrm{~mm}$, $5 \mu \mathrm{m}$ reversed phase C18 X-Terra column and a binary eluent made from solution A and solution $\mathrm{B}$. This eluent was used as a gradient from $5 \%$ of solution $\mathrm{B}$ to $30 \%$ of solution B over $20 \mathrm{~min}$. Flow rate was $20 \mathrm{ml} / \mathrm{min}$.

NMR spectra were recorded for dilute solution in DMSO $\mathrm{d}_{6}$ at $298 \mathrm{~K}$ using a Bruker ${ }^{\mathrm{TM}}$ spectrometers (500 and $600 \mathrm{MHz}$ ). All NMR spectra were referenced to tetramethylsilane (TMS $\left.\delta_{\mathrm{H}} 0, \delta_{\mathrm{C}} 0\right)$. All coupling constants are reported in Hertz $(\mathrm{Hz})$, and multiplicities are labelled s (singlet), bs (broad singlet), d (doublet), t (triplet), q (quartet), dd (doublet of doublets).

Analytical and spectral data of intermediate 2: 1H NMR (DMSO d $\left.\mathrm{d}_{6}\right) \delta \mathrm{ppm} 1.67(\mathrm{~d}, \mathrm{~J}=16.92 \mathrm{~Hz}$, $1 \mathrm{H}), 1.73-1.88(\mathrm{~m}, 5 \mathrm{H}), 2.08-2.14(\mathrm{~m}, 2 \mathrm{H}), 2.09(\mathrm{~d}, \mathrm{~J}$ $=9.59 \mathrm{~Hz}, 1 \mathrm{H}), 2.19(\mathrm{~d}, \mathrm{~J}=6.63 \mathrm{~Hz}, 1 \mathrm{H}), 2.51-2.57$ $(\mathrm{m}, 1 \mathrm{H}), 3.01(\mathrm{~s}, 2 \mathrm{H}), 3.12-3.21(\mathrm{~m}, 2 \mathrm{H}), 3.53-3.61(\mathrm{~m}$,
$2 \mathrm{H}), 3.68(\mathrm{td}, J=10.29,5.15$ $\mathrm{Hz}, 1 \mathrm{H}), 3.79$ (dd, $J=8.81$ $\mathrm{Hz}, J=5.50 \mathrm{~Hz}, 2 \mathrm{H}), 3.82-$ $3.86(\mathrm{~m}, 1 \mathrm{H}), 3.97(\mathrm{td}, J=$ $9.59 \mathrm{~Hz}, 5.76 \mathrm{~Hz}, 1 \mathrm{H}), 4.95-$ $5.02(\mathrm{~m}, 1 \mathrm{H}), 5.08(\mathrm{t}, \mathrm{J}=4.97$ $\mathrm{Hz}, 1 \mathrm{H}), 7.25-7.37(\mathrm{~m}, 5 \mathrm{H})$; $\mathrm{ES}+: 426[\mathrm{M}+1]$

\section{Analytical and spectral} data of ATR-4-OX (3): $1 \mathrm{H}$ NMR (DMSO d $\left.\mathrm{d}_{6}\right) \quad \delta \mathrm{ppm}$ 1.65-1.75 (m, 3H), 1.77-1.90 $(\mathrm{m}, 2 \mathrm{H}), 1.90-1.99(\mathrm{~m}, 2 \mathrm{H})$, $2.11(\mathrm{~d}, J=7.93 \mathrm{~Hz}, 2 \mathrm{H})$, $2.22(\mathrm{~d}, J=6.41 \mathrm{~Hz}, 1 \mathrm{H})$, $2.52-2.62(\mathrm{~m}, 2 \mathrm{H}), 3.03(\mathrm{~s}$, $3 \mathrm{H}), 3.18-3.27(\mathrm{~m}, 3 \mathrm{H}), 3.69$ $(\mathrm{dd}, J=10.38,5.49 \mathrm{~Hz}, 1 \mathrm{H})$, $3.81(\mathrm{dd}, J=8.85,5.49 \mathrm{~Hz}$, $2 \mathrm{H}), 3.87$ (d, J = $5.19 \mathrm{~Hz}$, $1 \mathrm{H}), 3.99(\mathrm{t}, J=9.61 \mathrm{~Hz}$, $1 \mathrm{H}), 4.63(\mathrm{t}, J=7.02 \mathrm{~Hz}, 2 \mathrm{H}), 7.27-7.38(\mathrm{~m}, 5 \mathrm{H}), 8.25$ $(\mathrm{d}, J=6.71 \mathrm{~Hz}, 2 \mathrm{H}), 8.45(\mathrm{~s}, 1 \mathrm{H}), 9.06(\mathrm{~d}, J=6.41 \mathrm{~Hz}$, 2H); ES+: $466.35[\mathrm{M}+1], 233.71$

Reactivation of tabun- or paraoxon-inhibited AChE. Tabun [ethyl N,N-dimethylphosphoroamidocyanidate] was purchased from NC Laboratory, Spiez, Switzerland, and paraoxon (O,O-diethyl-O-(4-nitrophenyl) phosphate) was purchased from Sigma Chemical Co., St. Louis, MO, USA. Enzyme substrate, acetylthiocholine iodide (ATCh), and thiol reagent, 5,5'-dithiobis(2-nitrobenzoic acid) (DTNB) were also from Sigma. Native human non-haemolysed erythrocytes were the source of AChE. They were obtained after blood centrifugation (20 min, $2500 \mathrm{rpm}$ ) and washing with sodium phosphate buffer $(0.1 \mathrm{M}, \mathrm{pH} 7.4)$ to remove residual plasma. Final dilution of erythrocytes in the enzyme activity assay was 400-fold. Undiluted erythrocytes were incubated with $5 \mu \mathrm{M}$ tabun or $1 \mu \mathrm{M}$ paraoxon for about $60 \mathrm{~min}$ to achieve $95-100 \%$ inhibition. The excess of organophosphorus compound was extracted with a 5-fold volume of hexane (De Jong et al., 1989). The inhibition mixture was diluted 10-times with sodium phosphate buffer $(0.1 \mathrm{M}, \mathrm{pH}$ 7.4) containing ATR-4-OX to start the reactivation. Final ATR-4-OX concentrations used for the reactivation were $0.05,0.2,0.5$ and $1.0 \mathrm{mM}$ in the case of tabun-inhibited, and $0.01,0.03$, $0.05,0.1,0.2,0.5$ and $1.0 \mathrm{mM}$ in the case of paraoxon-inhibited AChE. Reactivation of soman-inhibited AChE was not tested in vitro because of its fast aging (Worek et al., 2004). Reactivation measurements were done at $25^{\circ} \mathrm{C}$ on a CARY 300 spectrophotometer (Varian Inc., Australia). Detailed procedure of kinetic parameters determination was described previously (Čalić et al., 2006).

Studies in vivo. Male NIH/Ola Hsd mice (18-25 g body weight) were kept in Macrolone cages at $21^{\circ} \mathrm{C}$ with 12-h light and dark cycles. Animals were fed a standard diet (4RF21, Mucedola, Milano, Italy) with free access to water. In each of the in vivo experiments, 4 to 8 groups of 4 animals each were used.

Soman and tabun were purchased from NC Laboratory, Spiez, Switzerland, while paraoxon was purchased from Sigma Chemical Co., St. Louis, MO, USA. HI-6 [(1-(2-hydroxyiminomethylpyridinium)-3-(4carbamoylpyridinium)-2-oxapropane dichloride)] was synthesized in the Department of Toxicology, Faculty of Military Health Sciences, Hradec Kralove, Czech Republic. TMB-4 [1,3-bis(4-hydroxyiminomethylpyridinium) propane dibromide] was synthesized at Bosnalijek, Sara- 
jevo, Bosnia and Herzegovina. Atropine sulphate was purchased from Kemika, Zagreb, Croatia.

Acute toxicity $\left(\mathrm{LD}_{50}\right)$ of ATR-4-OX was based on $24 \mathrm{~h}$ mortality rates calculated according to Thompson (1947) and Weil (1952). LD 50 was evaluated from the results obtained with four doses of ATR-4-OX (dissolved in water); four animals were injected per dose.

The therapeutic effects against soman, tabun or paraoxon intoxication were tested by administering ATR4-OX alone or with atropine sulphate $(10.0 \mathrm{mg} / \mathrm{kg})$, immediately after OP. The currently used oximes HI-6 and TMB-4 were included for comparison. All oximes were used at two different doses, $5 \%$ and $25 \%$ of their respective $\mathrm{LD}_{50}$. OP compounds were given subcutaneously (s.c.) while therapy was administered intraperitoneally (i.p.). Mice were observed for $24 \mathrm{~h}$ and the antidotal efficacy of compounds was expressed as the protective index (PI) and maximal dose of poison (MDP). PI was calculated as the ratio of $\mathrm{LD}_{50}$ between $\mathrm{OP}$ with antidote and $\mathrm{LD}_{50}$ of OP in non-treated mice. The MDP was the highest multiple of the $\mathrm{LD}_{50}$ of OP that was fully counteracted (survival of all animals) by the antidotes.

This study was performed with the approval of the Ethics Committee of the Institute for Medical Research and Occupational Health in Zagreb, Croatia.

Assessment of genotoxicity on human lymphocytes. A blood sample was obtained from a healthy male donor (age 34 years, non-smoker) who gave his informed consent for participation in the study. The donor had not been exposed to diagnostic or therapeutic irradiations or to known genotoxic chemicals for one year before blood sampling. Venous blood $(20 \mathrm{ml})$ was collected under sterile conditions in vacutainer tubes (BD Vacutainer $^{\circledR}$ REF 367883, V = 4 ml; Becton Dickinson, Franklin Lakes, NJ, USA) containing lithium heparin (LH 68 I.U.) as an anticoagulant.

Lymphocyte isolation was performed as described elsewhere (Kopjar et al., 2007). Lymphocyte samples were incubated for $30 \mathrm{~min}$ in RPMI culture medium (Gibco) in vitro: (1) with ATR-4-OX, (2) with ATR-4-OX in the presence of S9 fraction $(10 \%, \mathrm{v} / \mathrm{v}$; Sigma-Aldrich Product Number S 2442) as the metabolic activator, according to the manufacturer's instructions. Concentrations of ATR-4-OX were calculated from values of doses applied in in vivo experiments. Corresponding negative controls (with and without S9) were studied in parallel. Evaluation of cell viability and apoptosis/necrosis was performed immediately after the treatment using the dye exclusion method (Duke \& Cohen, 1992). Three parallel tests with aliquots of the same sample were performed, and a total of 300 cells per sample were counted under a fluorescence microscope (Zeiss, Germany).

The comet assay was conducted under alkaline conditions, as described by Singh et al. (1988), and in neutral conditions according to Wojewódzka et al. (2002). Each slide was examined using a fluorescence microscope (Zeiss, Germany) equipped with an excitation filter of 515-560 $\mathrm{nm}$ and a barrier filter of $590 \mathrm{~nm}$. Using a black and white camera, the microscope image was transferred to a computer-based image analysis system (Comet Assay II, Perceptive Instruments Ltd., Suffolk, Halstead, UK).

The hOGG1 assay was performed according to Smith et al. (2006), and following the modified procedure described in Mladinić et al. (2009). We used commercially available hOGG1 FLARE ${ }^{\mathrm{TM}}$ Assay Module (Trevigen Inc., USA). Oxidative DNA damage was given as the difference between values obtained from slides trea- ted with hOGG1 enzyme and the Flare reaction buffer only. The $25 \times$ Flare buffer consisted of $250 \mathrm{mM}$ Hepes$\mathrm{KOH}, 250 \mathrm{mM}$ EDTA and $2.5 \mathrm{M} \mathrm{KCl}, \mathrm{pH}$ 7.4. Each slide was examined using a $250 \times$ magnification fluorescence microscope (Zeiss, Germany).

Statistical analyses. Statistical analyses were carried out with Statistica 5.0 (StatSoft, Tulsa, USA). In order to normalize distribution and equalize variances, a logarithmic transformation of data was applied. The extent of DNA damage, as recorded by the alkaline and neutral comet assays, was analysed considering the mean ( \pm standard error of the mean), median and range of the comet tail moment. Comparisons between samples were done using the one-way analysis of variance (ANOVA) and subsequently the Duncan test was applied for calculations concerning pair-wise comparisons. For the hOGG1-modified comet assay, the mean tail length and tail intensity values were calculated for each replicate slide. Means obtained with the buffer were compared with means for the corresponding enzyme-treated slide using the Wilcoxon Rank Sum Test. Comparisons between the values obtained for cell viability, apoptosis and necrosis in treated and control samples were conducted using the $\chi^{2}$ test. The level of statistical significance was set at $p<0.05$.

\section{RESULTS AND DISCUSSION}

The aim of the present study was to evaluate the antidotal potency against OP poisoning of a newly synthesized compound in which an atropine-like moiety is coupled with a pyridinium oxime. Since atropine is the mainstay of supportive therapy, we wanted to find out if it would have an impact on the overall efficacy of the conjugated molecule, ATR-4-OX.

We tested the potency of this new compound to reactivate tabun- or paraoxon-inhibited human erythrocyte AChE. Reactivation of paraoxon-inhibited AChE was very efficient. AChE activity was completely restored after only $20 \mathrm{~min}$, even when a low concentration of ATR-4-OX was applied. The overall reactivation rate constant for paraoxon, $k_{\mathrm{r}}$, was about $2000 \mathrm{~min}^{-1} \mathrm{M}^{-1}$ (Table 1). In contrast to paraoxon, ATR-4-OX was not efficient in reactivating tabun-inhibited $\mathrm{AChE}\left(k_{\mathrm{r}}=67\right.$ $\left.\mathrm{min}^{-1} \mathrm{M}^{-1}\right)$. Its reactivation was slow and a maximum of $90 \%$ was obtained in $7 \mathrm{~h}$ (Table 1 ). It seems that the atropine moiety did not affect the affinity for phosphylated $\mathrm{AChE}$, since the dissociation constant, $K_{\mathrm{Ox}}$, of about $100 \mu \mathrm{M}$ is similar to or even higher than that of HI6, 2-PAM or obidoxime (Worek et al., 2004). However,

Table 1. ATR-4-OX assisted reactivation of tabun- or paraoxoninhibited human erythrocyte AChE

\begin{tabular}{lll}
\hline & Tabun & Paraoxon \\
\hline ATR-4-OX $(\mathrm{mM})$ & $0.05-1.0$ & $0.01-1.0$ \\
$k_{\text {max }}\left(\mathrm{min}^{-1}\right)$ & $0.008 \pm 0.002$ & $0.17 \pm 0.02$ \\
$K_{\text {OX }}(\mathrm{mM})$ & $0.12 \pm 0.09$ & $0.07 \pm 0.03$ \\
$k_{\mathrm{r}}\left(\mathrm{min}^{-1} \cdot \mathrm{M}^{-1}\right)$ & $66.7 \pm 52.7$ & $2428 \pm 1080$ \\
React. $_{\max }(\%)$ & 90 & 100 \\
$t$ & $7 \mathrm{~h}$ & 20 min \\
\hline
\end{tabular}

$k_{\max }$ maximum first order reactivation rate constant; $K_{\mathrm{ox}}$, phosphylated enzyme-oxime dissociation constant; $k_{r}$ overall reactivation rate constant; React. max maximal reactivation obtained in time $t$. Constants $( \pm$ S.E.) were calculated from experimental data obtained in at least three experiments. 
Table 2. Effect of ATR-4-OXa with and without atropine compared to currently used oximes HI-6 and TMB-4 upon (s.c.) soman', tabunc and paraoxon ${ }^{d}$ toxicity in mice

\begin{tabular}{|c|c|c|c|c|c|c|c|c|}
\hline \multirow{2}{*}{ OP } & \multicolumn{2}{|l|}{ ATR-4-OX } & \multicolumn{2}{|c|}{ ATR-4-OX + atropine } & \multicolumn{2}{|c|}{ HI-6 + atropine } & \multicolumn{2}{|c|}{ TMB-4 + atropine } \\
\hline & $5 \% \mathrm{LD}_{50}$ & $25 \% \mathrm{LD}_{50}$ & $5 \% \mathrm{LD}_{50}$ & $25 \% \mathrm{LD}_{50}$ & $5 \% \mathrm{LD}_{50}$ & $25 \% \mathrm{LD}_{50}$ & $5 \% \mathrm{LD}_{50}$ & $25 \% \mathrm{LD}_{50}$ \\
\hline \multicolumn{9}{|c|}{ Soman } \\
\hline $\mathrm{PI}$ & 1.5 & 1.2 & 1.5 & 1.2 & 3.2 & 4.7 & - & - \\
\hline MDP & 1.3 & 0.8 & 1.3 & 1.0 & 2.0 & 3.2 & - & - \\
\hline \multicolumn{9}{|c|}{ Tabun } \\
\hline $\mathrm{PI}$ & 1.7 & 2.8 & 2.3 & 2.4 & $-f$ & - & 8.9 & 7.1 \\
\hline MDP & 1.3 & 2.0 & 2.0 & 2.0 & - & - & 4.0 & 5.0 \\
\hline \multicolumn{9}{|c|}{ Paraoxon } \\
\hline $\mathrm{PI}$ & nde & 5.7 & 11.6 & 22.5 & 20.0 & 23.8 & 15.0 & 16.8 \\
\hline MDP & nd & 1.6 & 10.0 & 16.0 & 12.6 & 16.0 & 12.6 & 12.6 \\
\hline
\end{tabular}

$\mathrm{PI}$, ratio of $\mathrm{LD}_{50}$ between OP with antidote and OP given alone. MDP, highest multiple of the OP LD ${ }_{50}$ counteracted by the oximes. a i.p. $\mathrm{LD}_{50}$ of ATR$4-\mathrm{OX}=10 \mathrm{mg} / \mathrm{kg}, \mathrm{HI}-6=635.2 \mathrm{mg} / \mathrm{kg}, \mathrm{TMB}-4=73.5 \mathrm{mg} / \mathrm{kg} .{ }^{\mathrm{b}}$ s.C. $\mathrm{LD}_{50}$ of soman was $126 \mu \mathrm{g} / \mathrm{kg} .{ }^{\mathrm{c}}$ s.C. $\mathrm{LD}_{50}$ of tabun was $317.5 \mu \mathrm{gg} / \mathrm{kg}$. ${ }^{\text {d }}$ s.C. LD ${ }_{50}$ of paraoxon was $864.3 \mu \mathrm{g} / \mathrm{kg}$. e nd = could not be determined. $\mathrm{f}^{\mathrm{N}}$ "" $=$ not performed.

stabilisation of ATR-4-OX in tabun-inhibited AChE was non-productive, implying that nucleophilic displacement occurs at a very low rate $\left(k_{\max }\right.$ for tabun and paraoxoninhibited AChE was 0.008 and $0.17 \mathrm{~min}^{-1}$, respectively). For comparison, the maximum reactivation constant, $k_{\max }$, of the most efficient reactivator of tabun-inhibited AChE, K203, was 0.13 min $^{-1}$ (Kovarik et al., 2009).

In vivo antidotal activity of the new compound was evaluated in the therapy of tabun, soman or paraoxon poisoning in mice. The tested oxime was toxic to mice; its $\mathrm{LD}_{50}$ was $10 \mathrm{mg} / \mathrm{kg}$ body weight, which is considerably lower than that for HI-6 $(635.2 \mathrm{mg} / \mathrm{kg})$ or TMB-4 (73.5 mg/kg) (Čalić et al., 2006). The first symptoms of the oxime toxicity appeared shortly after i.p. administration and some animals died very soon. Other mice partially recovered at $24 \mathrm{~h}$. Muscle fasciculation and tremor generally occurred within 5-10 min. Symptoms such as ataxia, dyspnoea, tremor, fasciculation, and salivation persisted for 30-60 min, after which all symptoms became more pronounced and persisted for up to $3 \mathrm{~h}$, while tremor could be provoked for up to $24 \mathrm{~h}$. Based on the persistence of toxicity symptoms in mice, it seems that the effects of the atropine moiety in attenuating such symptoms are questionable.

Table 2 presents evaluated antidotal efficiency of ATR4-OX in soman, tabun and paraoxon poisoning applied at two doses. Severe signs of toxicity were observed in all animals despite antidotal treatment. Muscle fasciculation and tremor generally occurred within 1-2 min after poisoning. Convulsions appeared with a latency of 3-4 min. During the acute phase, all animals exhibited dyspnoea and cyanosis. Animals that survived remained active for $24 \mathrm{~h}$. Although ATR-4-OX is a conjugated compound consisting of an atropine-like moiety, poisoning symptoms were not surpressed. In addition, survival rates after application of ATR-4-OX alone were very low in contrast to therapy with ATR-4-OX plus atropine (Table 2). This is in accord with previously published data which indicate that the application of conventional oximes alone is not satisfactory (Bošković et al., 1980; Bošković et al., 1984; Dawson, 1994). Also, it has previously been shown that after the administration of atropine alone, protective index (PI) is below 2 in many cases (Dawson, 1994). ATR-4-OX applied with atropine was very effective against paraoxon poisoning at both applied doses, showing survival of all animals after administration of 10.0 and $16.0 \mathrm{LD}_{50}$ doses of paraoxon. However, it showed weak antidotal activity for soman and tabun poisoning, especially in comparison with HI-6 and TMB-4, respectively.
Figure 2. Viability, apoptosis and necrosis in lymphocytes treated with ATR-4-OX without and with metabolic activation (S9)

Three-hundred cells per sample per experimental point were scored. CON, negative control; (a) significantly higher viability as compared to matched control sample (S9-CON); (b) significantly higher viability as compared to sample treated with higher concentration of conjugate in the presence of S9; c, significantly lower incidence of necrotic cells as compared to matched control sample (S9CON) $\left(p<0.05, x^{2}\right.$ test). 

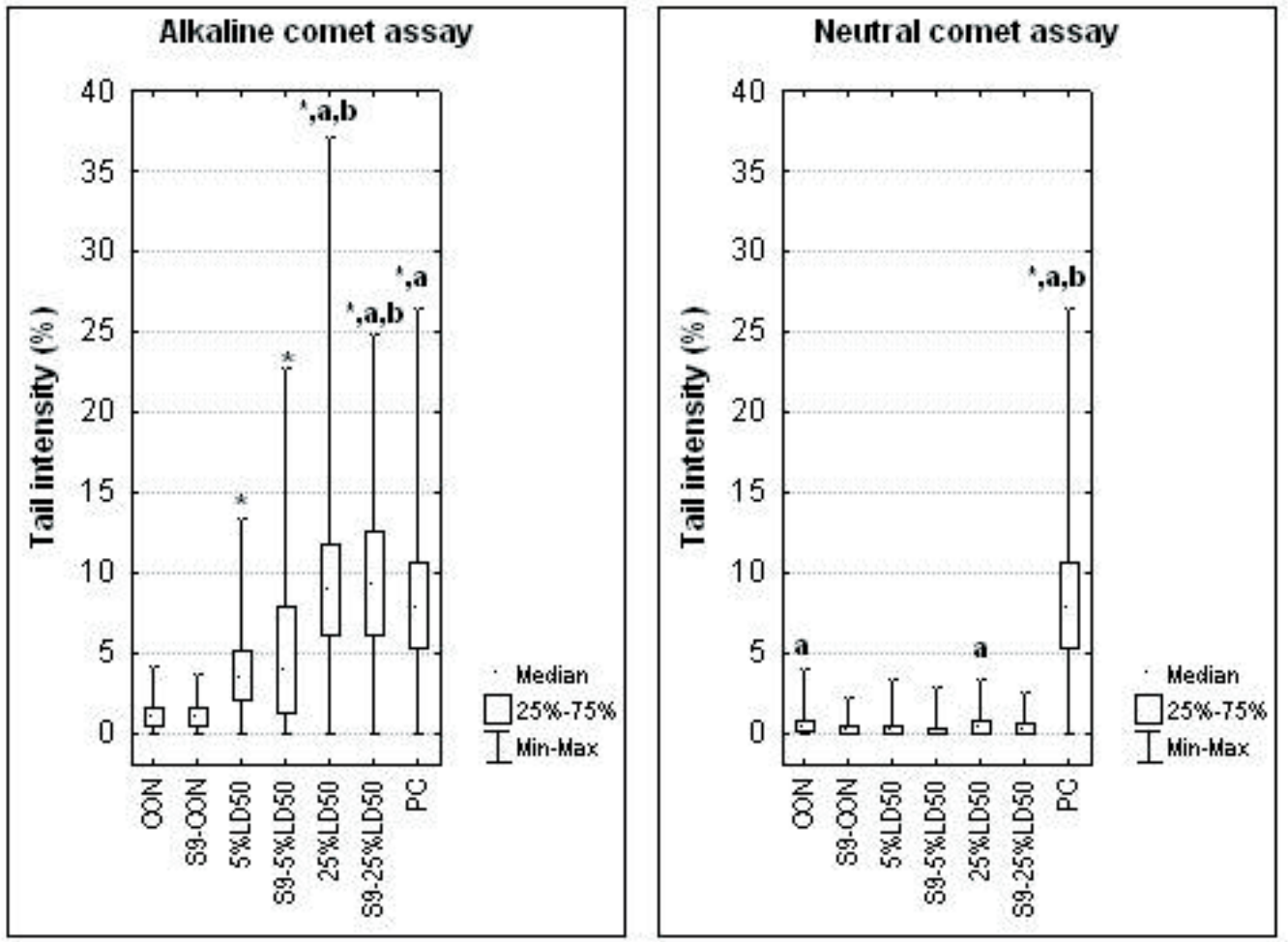

Figure 3. DNA damage in lymphocytes treated with ATR-4-OX without and with metabolic activation (S9)

Three-hundred individual comets per sample were measured. CON, negative control; PC, positive control (cells treated with 100 mM hydrogen peroxide on ice for $10 \mathrm{~min}$ ). Significantly increased values: * compared to matched negative control; (a) compared to matched sample treated with $5 \% \mathrm{LD}_{50} ;$ (b) compared to positive control.

It should be mentioned that soman binds irreversibly to AChE within minutes of exposure, underscoring the importance of immediate administration of an oxime (Antonijević \& Stojiljković, 2007).

Evaluation of cell viability, apoptosis/necrosis measurements and comet assays were performed to estimate the potential cyto/genotoxic effects of the new compound in human peripheral lymphocytes. ATR-4OX did not significantly impair the viability of lymphocytes in samples without metabolic activator S9 or in samples treated in the presence of S9 (Fig. 2).
However, in samples treated with ATR-4-OX administered at a concentration of $25 \% \mathrm{LD}_{50}$ with metabolic activation, slightly lower lymphocyte viability $(92.34 \%)$ was observed as compared to the sample treated without S9 (95.67\%). The difference was principally due to a non-significant increase of apoptotic cells $(5.33 \%$ vs. $2.33 \%)$. The conjugate applied at the lower dose with metabolic activation significantly increased lymphocyte viability compared to the corresponding control sample $\left(96.33 \%\right.$ vs. $90.67 \% ; P=0.0049, \chi^{2}$ test $)$ and compared to the sample treated with the higher concentration $\left(96.33 \%\right.$ vs. $92.34 \% ; P=0.0341, \chi^{2}$ test).

Table 3. Results of hOGG1-modified comet assay

\begin{tabular}{|c|c|c|c|c|c|c|c|}
\hline \multirow{2}{*}{ Sample } & \multirow{2}{*}{ Parameter } & \multicolumn{3}{|l|}{$-\mathrm{S9}$} & \multicolumn{3}{|l|}{$+\mathrm{S} 9$} \\
\hline & & Flare buffer & hOGG1 & $\begin{array}{l}\text { Oxidative } \\
\text { damage }\end{array}$ & Flare buffer & hOGG1 & $\begin{array}{l}\text { Oxidative } \\
\text { damage }\end{array}$ \\
\hline $\begin{array}{l}\text { Negative } \\
\text { control }\end{array}$ & $\begin{array}{l}\text { Tail length } \\
\text { Tail intensity }\end{array}$ & $\begin{array}{c}11.34 \pm 0.32 \\
0.43 \pm 0.19\end{array}$ & $\begin{array}{c}12.09 \pm 0.32 \\
0.59 \pm 0.25\end{array}$ & $\begin{array}{l}0.75 \\
0.16\end{array}$ & $\begin{array}{c}11.08 \pm 0.13 \\
0.59 \pm 0.12\end{array}$ & $\begin{array}{c}11.74 \pm 0.12 \\
0.86 \pm 0.20\end{array}$ & $\begin{array}{l}0.62 \\
0.27\end{array}$ \\
\hline $\begin{array}{l}\mathrm{H}_{2} \mathrm{O}_{2} \\
10 \mathrm{mM}\end{array}$ & $\begin{array}{l}\text { Tail length } \\
\text { Tail intensity }\end{array}$ & $\begin{array}{l}21.21 \pm 0.75 \\
12.20 \pm 1.42\end{array}$ & $\begin{array}{l}28.03 \pm 1.30 \\
22.61 \pm 2.46\end{array}$ & $\begin{array}{c}6.82^{\mathrm{b}} \\
10.41^{\mathrm{b}}\end{array}$ & ' & $\begin{array}{l}1 \\
1\end{array}$ & / \\
\hline $\begin{array}{l}\text { ATR-4-OX } \\
25 \% \text { LD }_{50}\end{array}$ & $\begin{array}{l}\text { Tail length } \\
\text { Tail intensity }\end{array}$ & $\begin{array}{c}12.02 \pm 0.19 \\
0.84 \pm 0.17\end{array}$ & $\begin{array}{c}12.26 \pm 0.22 \\
1.25 \pm 0.22\end{array}$ & $\begin{array}{l}0.24 \\
0.41\end{array}$ & $\begin{array}{c}12.62 \pm 0.28 \\
1.44 \pm 0.42\end{array}$ & $\begin{array}{c}13.02 \pm 0.21 \\
1.57 \pm 0.31\end{array}$ & $\begin{array}{l}0.40 \\
0.13\end{array}$ \\
\hline $\begin{array}{l}\text { ATR-4-OX } \\
5 \% \mathrm{LD}_{50}\end{array}$ & $\begin{array}{l}\text { Tail length } \\
\text { Tail intensity }\end{array}$ & $\begin{array}{c}11.96 \pm 0.12 \\
0.55 \pm 0.08\end{array}$ & $\begin{array}{c}13.20 \pm 0.50 \\
2.40 \pm 0.86\end{array}$ & $\begin{array}{l}1.24^{\mathrm{a}} \\
1.85^{\mathrm{a}, \mathrm{c}}\end{array}$ & $\begin{array}{l}11.76 \pm 0.12 \\
0.29 \pm 0.05\end{array}$ & $\begin{array}{c}12.95 \pm 0.16 \\
1.02 \pm 0.13\end{array}$ & $\begin{array}{l}1.19 \\
0.73\end{array}$ \\
\hline
\end{tabular}

One hundered individual comets per experimental point were measured. Tail length ( $\mu$ m) and tail intensity (\%) are expressed as mean values \pm S.E.M. Oxidative damage calculated by subtracting the means for tail length and intensity obtained by buffer treatment from the corresponding means obtained by enzymatic treatment. Statistics: ${ }^{a} p<0.05$ and ${ }^{b} p<0.01$ compared to the control; ${ }^{c} p<0.05$ compared to the treatment with $\mathrm{S} 9$. 
Moreover, the conjugate applied at the lower dose with metabolic activation significantly decreased the incidence of necrotic cells as compared to the corresponding control sample $(1.00 \%$ vs. $3.66 \%, P=0.0305$, $\chi^{2}$ test) (Fig. 2). In the alkaline comet assay, both tested concentrations evoked an increase in tail intensity compared to the negative control, though the values recorded in different samples incubated with and without metabolic activation did not differ significantly (Fig. 3). Mean tail intensity measured in the sample treated with the lower concentration of the conjugate without S9 was $3.86 \pm 2.53 \%$ vs. $4.88 \pm 4.12 \%$ in the sample treated with S9. Mean tail intensity measured in the sample treated with the higher concentration of the conjugate without S9 was $9.06 \pm 4.76 \%$ and $9.43 \pm 4.66 \%$ in the sample treated with S9. Results of the neutral comet assay show that treatment with the oxime at both tested concentrations did not significantly influence the integrity of lymphocyte DNA (Fig. 3). Since the hOGG1-modified comet assay represents the most sensitive modification of the assay, which allows the detection of oxidative DNA damage, we also employed this test to evaluate whether ATR4-OX treatment produced this type of DNA damage. A significant level of $8-O$ OhdG, which corresponded to $1.24 \mu \mathrm{m}$ for tail length and $1.85 \%$ for tail intensity, was detected only at $5 \% \mathrm{LD}_{50}$ of the conjugate administered without metabolic activation. This qualifies the induced oxidative damage as biologically irrelevant (Collins, 2004), since the corresponding values measured in the sample treated with $\mathrm{H}_{2} \mathrm{O}_{2}$ were $6.82 \mu \mathrm{m}$ for tail length and $10.41 \%$ for tail intensity (Table 3). Furthermore, these results suggest that the DNA lesions detected by the alkaline comet assay are not mediated by oxidative stress induction. Taken together, the findings of this study indicate an acceptable genotoxic profile of ATR-4-OX assessed on human lymphocytes.

In conclusion, it seems that ATR-4-OX has a therapeutic effect that is related to the reactivation of phosphylated AChE but not to receptor antagonization. Based on the obtained results, we are aware that a compound with such a high acute toxicity compared to the currently used oximes has no future as an antidote in organophosphorus compounds poisoning. However, its acceptable cytotoxic and genotoxic profiles suggest that ATR-4-OX might be used as a source molecule for further development. Therefore, even if this conjugated compound has its limitations, the concept of creating a bifunctional antidote should not be completely discarded.

\section{Acknowledgements}

The authors thank Jasna Mileković and Marija Kramarić for technical assistance, and Linda Zanella, M.Sc. for helpful language advice.

This work was supported by the Ministry of Science, Education and Sports of the Republic of Croatia (Grant Nos. 022-0222148-2139, 022-0222148-2889 and 0220222148-2137).

\section{REFERENCES}

Antonijević B, Stojiljković MP (2007) Unequal efficacy of pyridinium oximes in acute organophosphate poisoning. Clin Med Res 5: 71-82.
Bošković B, Tadić V, Kušić R (1980) Reactivating and protective effects of Pro-2-PAM in mice poisoned with paraoxon. Toxicol Appl Pharmacol 55: 32-36.

Bošković B, Kovačević V, Jovanović D (1984) PAM-2 Cl, HI-6 and HGG-12 in soman and tabun poisoning. Fundam Appl Toxicol 4: 106-115.

Collins AR (2004) The comet assay for DNA damage and repair: principles, applications, and limitations. Mol Biotechnol 26: 249-261.

Čalić M, Lucić Vrdoljak A, Radić B, Jelić D, Jun D, Kuča K, Kovarik $Z$ (2006) In vitro and in vivo evaluation of pyridinium oximes: mode of interaction with acetylcholinesterase, effect on tabun- and soman-poisoned mice and their cytotoxicity. Toxicology 219: 85-96.

Dawson RM (1994) Review of oximes available for the treatment of nerve agent poisoning. I Appl Toxicol 14: 317-331.

De Jong LPA, Verhagen MAA, Langenberg JP, Hagedorn I, Löffler M (1989) The bispyridinium-dioxime HLÖ-7. A potent reactivator for AChE inhibited by the stereoisomers of tabun and soman. Biochem Pharmacol 38: 633-640.

Duke RC, Cohen JJ (1992) Morphological and biochemical assays of apoptosis. In Current Protocols in Immunology. Coligan JE, Kruisbeal AM, eds, pp 1-3. John Willey and Sons, New York.

Kim TH, Kuča K, Jun D, Jung YS (2005) Design and synthesis of new bis-pyridinium oxime reactivators for acetylcholinesterase inhibited by organophosphorous nerve agents. Bioorg Med Chem Let 15: 2914-2917.

Kopjar N, Želježić D, Lucić Vrdoljak A, Radić B, Ramić S, Milić M, Gamulin M, Pavlica V, Fučić A (2007) Irinotecan toxicity to human blood cells in vitro - relationships between various biomarkers. $B a$ sic Clin Pharmacol Toxicol 100: 403-413.

Kovarik Z, Čalić M, Šinko G, Bosak A (2007) Structure-activity approach in the reactivation of tabun-phosphorylated human acetylcholinesterase with bispyridinium para-aldoximes. Arb Hig Rada Toksikol 58: 201-209.

Kovarik Z, Čalić M, Bosak A, Šinko G, Jelić D (2008) In vitro evaluation of aldoxime interactions with human acetylcholinesterase. Croat Chem Acta 81: 47-57.

Kovarik Z, Lucić Vrdoljak A, Berend S, Čalić M, Kuča K, Musilek K, Radić B (2009) Evaluation of oxime K203 as antidote in tabun poisoning. Arb Hig Rada Toksikol 60: 19-25.

Kovarik Z, Katalinić M, Śinko G, Binder J, Holas O, Jung Y-S, Musilova L, Jun D, Kuča K (2010) Pseudo-catalytic scavenging: searching for a suitable reactivator of phosphorylated butyrylcholinesterase. Chem Biol Interact 187: 167-171.

Makarevich I, Gubin Y (2006) Quaternary salts of alkaloids. Chem Na Cmpd 4: 473-476.

Mladinić M, Berend S, Lucić Vrdoljak A, Kopjar N, Radić B, Želježić D (2009) Evaluation of genome damage and its relation to oxidative stress induced by glyphosate in human lymphocytes in vitro. Environ Mol Mutagen 50: 800-807.

Namba T, Nolte CT, Jackrel J, Grob D (1971) Poisoning due to organophosphate insecticides. Acute and chronic manifestations. Am J Med 50: 475-492.

Pang YP, Kollmeyer TM, Hong F, Lee JC, Hammond PI, Haugabouk SP, Brimijoin S (2003) Rational design of alkylene-linked bis-pyridiniumaldoximes as improved acetylcholinesterase reactivators. Chem Biol 10: 491-502.

Poziomek EJ, Hackley BE, Steinberg GM (1958) Pyridinium aldoximes. J Org Chem 23: 714-717.

Radić B, Lucić Vrdoljak A, Želježić D, Fuchs N, Berend S, Kopjar N (2007) Evaluation of HI-6 oxime: potential use in protection of human acetylcholinesterase inhibited by antineoplastic drug irinotecan and its cyto/genotoxicity in vitro. Acta Biochim Pol 54: 583-593.

Schmeller T, Sporer F, Sauerwein M, Wink M (1995) Binding of tropane alkaloids to nicotinic and muscarinic acetylcholine receptors. Pharmazie 50: 493-495.

Singh NP, McCoy MT, Tice RR, Schneider LL (1988) A simple technique for quantitation of low levels of DNA damage in individual cells. Exp Cell Res 175: 184-191.

Smith CC, O'Donovan MR, Martin EA (2006) hOGG1 recognizes oxidative damage using comet assay with greater specificity than FPG or ENDOIII. Mutagenesis 21: 185-190.

Sugai S, Kajiwara Y, Kubota K (1985) Pharmacological properties of quaternary atropinium derivatives. Yakugaku Zasshi 105: 183-187.

Thompson WR (1947) Use of moving averages and interpolation to estimate median-effective dose. Bacteriol Rev 11: 115-145.

Weil CS (1952) Tables for convenient calculation of median-effective dose (LD50 or ED50) and instruction in their use. Biometrics 8: $249-263$.

Wojewódzka M, Grądzka I, Buraczewska I (2002) Modified neutral comet assay for human lymphocytes. Nukleonika 47: 1-5.

Worek F, Thiermann H, Szinicz L, Eyer P (2004) Kinetic analysis of interactions between human acetylcholinesterase, structurally different organophosphorus compounds and oximes. Biochem Pharmacol 68: $2237-2248$ 